\title{
83. Tissue Culture of Skin in Acatalasemia and Hypocatalasemia
}

\author{
By Isamu Kitamura,* Masana Ogata, ${ }^{* *}$ \\ and Shigeo TAKAHARA*** \\ (Comm. by T. FuruhatA, M.J.A., July 12, 1962)
}

\section{Introduction}

Acatalasemia $^{1,2)}$ is a rare congenital constitutional abnormality characterized by an apparent lack of catalase activity not only in the blood but also in the tissues of other organs such as the nasal and oral cavities, the pharynx, bone marrow, liver, appendix, and abdominal muscles as far as our studies are concerned.

Furthermore, it has been found that there are hypocatalasemic individuals $\mathrm{s}^{3)}$ in the acatalasemic families, showing about one half of normal catalase value. Such hypocatalasemic individuals can be found even in the general populace and significantly it is proved that hypocatalasemia is a carrier state of acatalasemia gene.

Krooth et al. ${ }^{4}$ reported that they succeeded in tissue culture of skin of acatalasemic, hypocatalasemic, and normal individuals.

Provided the cells proliferated by the tissue culture of skin from the above individuals can be used for the further works from time to time, it seems that such cells would serve us to bring some important views on the biological significance of catalase and the generation of $\mathrm{H}_{2} \mathrm{O}_{2}$ in the living cells.

With the purpose to obtain these biological informations we conducted successfully the tissue culture of skin specimens from normal, hypocatalasemic and acatalasemic individuals for several generations. In this paper the results of these studies are presented.

\section{Materials and Methods}

Materials. The forearm skin specimens obtained from acatalasemic and hypocatalasemic individuals and from the normal individuals as the control served as materials.

The. blood catalase activities in donors were 0.07 in acatalasemia, 1.98 in hypocatalasemia and 5.25 in normal subject, expressed by Kcat. ${ }^{3)}$

Methods. Harnden's method ${ }^{5)}$ was employed for the skin tissue

This work was aided in part by the Rockefeller Foundation.

* Dept. of Pediatric Okayama University Medical School.

** Dept. of Public Health, Okayama Univ. Med. School.

*** Dept. of Otolaryngology, Okayama Univ. Med. School. 
culture and it was conducted by I. Kitamura, one of the authors, at the Pediatric Department.*

As for the culture, the growth medium was made following Harnden's prescription, to have 60 per cent of tissue culture medium 199 (Difco Co.), 20 per cent of human serum and 20 per cent of chick embryo extract.

In the primary culture of the skin tissue in the above Harnden's medium, the transparent fusiform fibroblasts began to appear around the original tissue from the fifth to seventh day. Then, the first subculture of fibroblast was carried out on the twelfth day in acatalasemia and on the sixteenth day in hypocatalasemia and normal, with the use of trypsin for detaching the proliferative cells from the wall of test tube.

\section{Results}

Up to date we have succeeded in the successive subculture to the eighth generation with acatalasemic fibroblasts while to the sixth generation with the hypocatalasemic and to the third with the normal, respectively. Phase-contrast microscopic figures of acatalasemic fibroblasts in culture are shown in Fig. 1-a and 1-b.

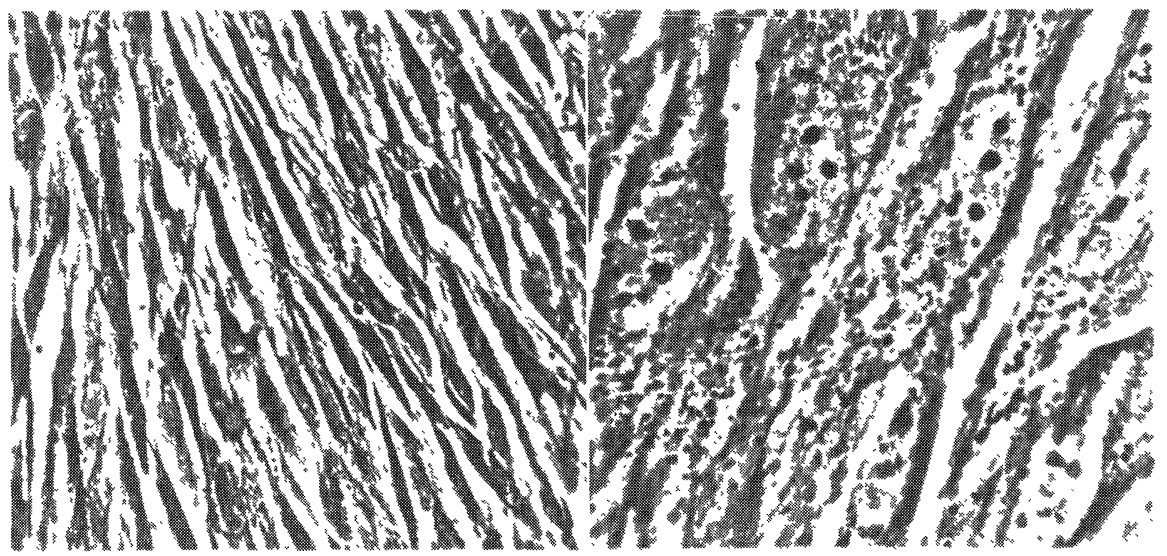

$$
\begin{array}{ll}
\text { a. } \times 200 & \text { b. } \times 1000
\end{array}
$$

Fig. 1. Phase-contrast photomicrographs of acatalasemic fibroblasts, the second generation.

In order to determine the presence or absence of the catalase activity of the proliferative fibroblasts, the next procedures were taken; the cells were cultured on the coverglass placed in the test tube and the coverglass was taken out and put on a slideglass with cell-side down. Then, a droplet of one per cent $\mathrm{H}_{2} \mathrm{O}_{2}$ was placed from a pipette at the margin of the coverglass to spread over the

\footnotetext{
* Director: Prof. E. Hamamato.
} 
surface of the cells. In the microscopic observation conducted immediately after spreading $\mathrm{H}_{2} \mathrm{O}_{2}$, bubbles appeared in various parts of the field in hypocatalasemia (Fig. 2-a. 2-b) and normal, indicating the presence of catalase activity, but not in acatalasemia.

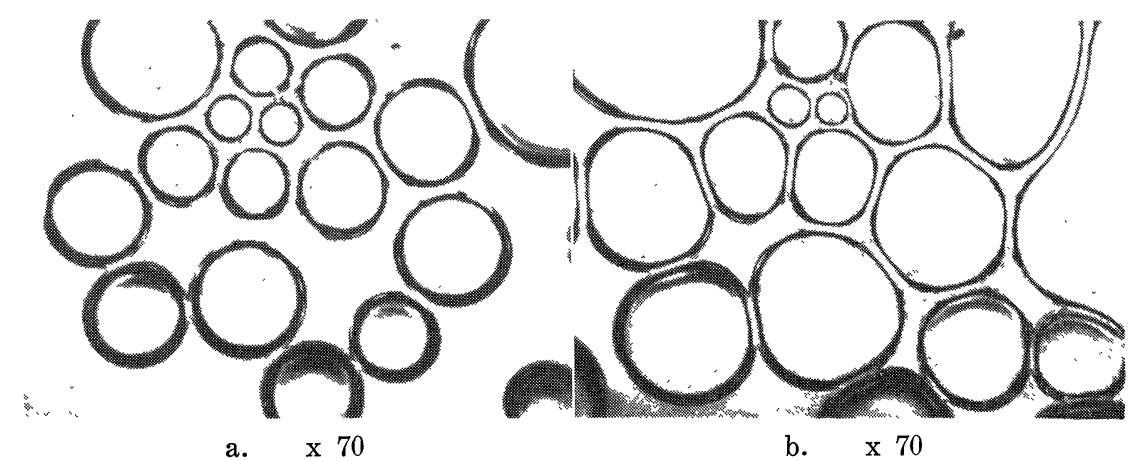

Fig. 2. Bubble formation with hypocatalasemic fibroblasts, the fourth generation, after exposure to one per cent $\mathrm{H}_{2} \mathrm{O}_{2}$.

Note the enlargement of the bubbles in b. as compared with those in a. due to the generation of oxygen gas.

Fig. 2-b. was taken 20 seconds ofter Fig. 2-a.

\section{Conclusion}

1. The tissue culture of skin cells from normal, hypocatalasemic and acatalasemic subjects has been successfully conducted, lasting for several generations. Attempts will be made to establish strains from these fibroblasts through subculture.

2. In the microscopic observation at the exposure of the cultured cells to $\mathrm{H}_{2} \mathrm{O}_{2}$ it was proved that catalase activity was demonstrated in the case of the cultured cells from normal and hypocatalasemia but none in the case of acatalasemic cells.

\section{Acknowledgement}

Our acknowledgement is due to Prof. E. Hamamoto for his kind encouragement during this work and also we wish to thank Dr. $\mathrm{H}$. Sanada for taking the phase-contrast microscopic pictures of the proliferative cells in culture.

\section{References}

1) Takahara, S.: Lancet, 6, 1101 (1952).

2) Takahara, S., Ogura, Y., and Doi, K.: Acta Med. Okayama, 13, 209 (1959).

3) Takahara, S., Hamilton, H. B., Neel, J. V., Kobara, T. Y., Ogura, Y. and Nishimura, E. T.: J. Clin. Invest., 39, 610 (1960).

4) Krooth, R. S., Howell, R. R., and Hamilton, H. B.: J. Exp. Med., 115, 313 (1962).

5) Harnden, D. G.: Brit. J. Exp. Path., 41, 31 (1960). 